
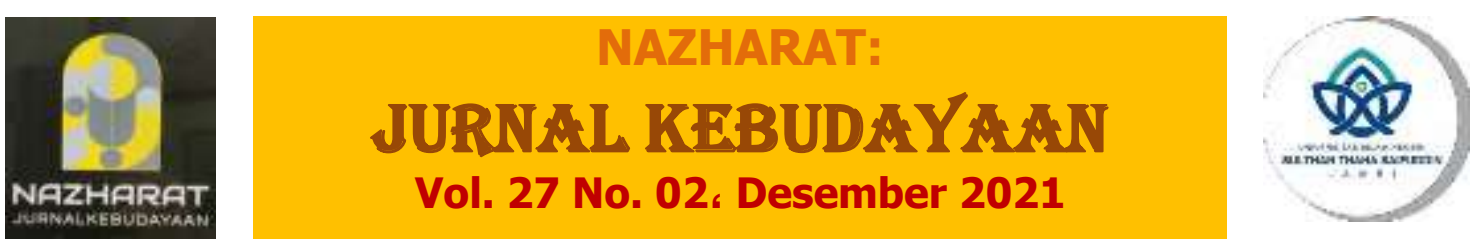

\title{
DECODING DALAM IKLAN "KELAS POLIGAMI SAAT NEW NORMAL: CARA KILAT DAPAT ISTRI EMPAT"
}

\author{
Hesti Fuji Lestari \\ Kajian Budaya dan Media Sekolah Pascasarjana, Universitas Gadjah Mada \\ Jl. Teknika Utara, Sleman, Yogyakarta \\ hesti.puji.lestari@mail.ugm.ac.id
}

Iklan menjadi salah satu alat untuk menyebarkan ideologi sebuah kelompok tertentu. Sebab iklan tak hanya berposisi sebagai alat marketing namun juga menimbun banyak makna yang tersirat di dalamnya. Makalah ini akan membahas tentang tahapan decoding dalam iklan "Kelas Poligami Cara Kilat dapat Istri Empat". Metode mata uang tanda milik Judith Williamson akan menjadi alat utama untuk membedah struktur dan ideologi yang terkandung dalam iklan tersebut. Hasilnya, pilihan kata, pilihan foto pemateri, penanda hingga petanda iklan kelas poligami "Kelas Poligami saat New Normal Cara Kilat dapat Istri Empat" tersebut mengandung makna yang begitu dalam.

Advertising is a tool to spread the ideology of a particular group. Because advertising is not only a marketing tool but also hoarding the many meanings implied in it. This paper will discuss the stages of decoding in polygamy class advertisements "Quick Ways to Get a Wife of Four". Judith Williamson's method of sign currency will be the main tool for dissecting the structure and ideology contained in the advertisement. As a result, the choice of words, the choice of photos of the presenters, markers to markers for the polygamy class advertisement "Quick Ways to Get a Wife of Four", have deep meaning.

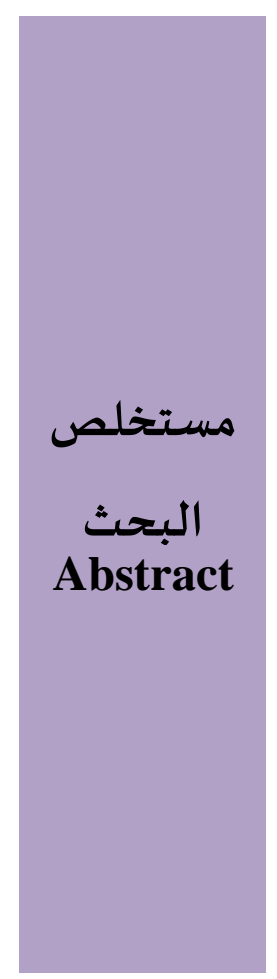

Keywords: Decoding, Advertising, Judith Williamson, Polygamy.

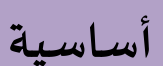

Keyword

\section{INTRODUCTION (مقدمة)}

Kajian tentang iklan masih menjadi sesuatu yang menarik untuk dibahas. Sebab, produksi iklan dewasa ini semakin jelas menampakkan perannya dalam internalisasi ideologi 
dari pihak-pihak tertentu kepada khalayak. Jelas bahwa iklan berfungsi untuk menjual komoditas. Namun, ia juga mempunyai fungsi yang lain, menggantikan fungsi seni dan agama, yaitu menciptakan struktur-struktur makna (Williamson 1979: 11-12). Sebab, dalam fungsinya untuk menjual, iklan melibatkan proses. Ia tidak hanya membicarakan soal kualitas yang inheren dan atribut-atribut dari suatu produk, melainkan juga cara-cara yang dengannya iklaniklan itu membuat properti-properti di atas mempunyai arti tertentu bagi kita (Williamson 1979:12). Tak dapat dipungkiri, iklan merupakan salah satu produk dari media yang bisa digunakan untuk menyebarluaskan sebuah ideologi. Apalagi jika iklan tersebut secara masif dilakukan. Judith Williamson juga sempat meyinggung tentang iklan yang bekerja secara masif akan membuat sebuah fenomena terdengar seperti wajar-wajar saja (taken for granted) bagi sebagaian orang. Padahal dalam iklan tersebut terkandung ideologi yang kuat.

Beberapa waktu lalu, sebuah iklan tentang kelas online menjadi bahan yang menarik untuk dibahas. Alih-alih menawarkan kelas untuk menunjang skill individu di era yang serba online seperti saat ini, iklan tersebut justru menawarkan kelas poligami dengan tagline "Cara Kilat Dapat Istri Empat". Jika dilihat secara tidak kritis, tak ada yang salah dalam iklan tersebut. Memiliki istri empat mungkin menjadi dambaan bagi sebagian besar pria. Oleh sebab itu, sebuah organisasi mengambil celah untuk membuat keinginan "pria" tersebut lekas terwujud dengan mengadakan kelas online degan tagline "Cara Kilat dapat Istri Empat". Apalagi bagi pemeluk agama tertentu, memiliki empat istri tidaklah salah menurut syariat.

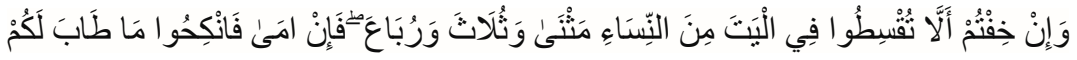

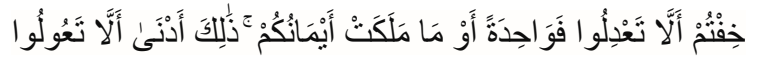

"Dan jika kamu takut tidak akan dapat berlaku adil terhadap (hak-hak) perempuan yatim (bilamana kamu mengawininya), maka kawinilah wanitawanita (lain) yang kamu senangi: dua, tiga, atau empat. Jika kamu takut tidak akan berlaku adil maka kawinilah seorang saja. Atau budak-budak yang kamu miliki. Hal tersebut lebih dekat kepada tidak berbuat aniaya". (Q.S An-Nisaa 4:3) 
Makalah ini akan membahas tentang tahapan decoding dalam iklan kelas poligami "Cara Kilat dapat Istri Empat. Metode mata uang tanda milik Judith Williamson akan menjadi alat utama untuk membedah struktur dan ideologi yang terkandung dalam iklan tersebut. Seperti diketahui, semiotika adalah ilmu yang mempelajari soal tanda. Semiotika Pierce merupakan semiotik analitis. Nurgiyantoro (2012: 41) menyebutkan bahwa dalam teori Pierce sesuatu itu dapat disebut sebagai tanda jika ia mewakili sesuatu yang lain. Dalam kajiannya, Pierce membagi tiga elemen tanda (hubungan triadik) yang disebut dengan segitiga makna. Segitiga makna ini mencakup tanda (ground), objek, dan interpretant. Adapun ketiga elemen tersebut, dijelaskan oleh Pierce sebagai proses semiosis. Sementara Judith Williamson meyebut bahwa iklan sangat pervasif. Karena sifatnya lintas media, iklan seakan mempunyai dunianya sendiri terlepas dari bentuk materialnya. Menganalisis iklan dalam bentuk materialnya dapat mencegah kita dari kecenderungan memahami material palsunya dan kecenderungannya mendistorsi dunia nyata yang ada di sekitar layar dan lembaran kertas (1979:11).

Dalam iklan Kelas Poligami "Cara Kilat dapat Istri Empat" mengandung stereotip terhadap perempuan. Stereotip adalah pandangan atau cara pandang terhadap suatu kelompok sosial dimana cara pandang tersebut kemudian digunakan pada setiap anggota kelompok (Mufid, 2019: 260). Dengan kata lain, stereotip adalah penilaian terhadap seseorang hanya berdasarkan persepsi terhadap suatu kelompok di mana orang tersebut dapat dikategorikan. Stereotip juga kerap diartikan sebagai ejekan, gambaran-gambaran atau angan-angan atau tanggapan tertentu terhadap individu atau kelompok yang dikenai prasangka yang cenderung tidak benar. Individu yang melakukan stereotip terhadap suatu kelompok atau golongan, sikap stereotip ini sulit berubah, meskipun apa yang menjadi stereotip berbeda dengan kenyataan. Dalam iklan yang menjadi objek kajian ini, stereotifikasi gender jelas. Dengan sedikit perbedaan atribut yang dimiliki, perempuan kerap dianggap sebagai objek. Seolah-olah, tugas utama perempuan dilahirkan ke dunia ini hanya untuk melayani (dan kemudian berbakti) kepada gender tertentu alias laki-laki. Padahal jika dilihat secara manusia, semua gender memiliki hak dan kewajiban yang sama dalam hidup.

Mengenai poligami ini, ada ungkapan menarik yang dikutip al Bajuri dari Ibn`Abd as Salam yang mengatakan: "Dahulu, pada zaman syari at Musa a.s., perempuan dibolehkan dinikahi tanpa batas untuk kemaslahatan laki-laki. Pada zaman syari at Isa a.s., tidak diperbolehkan dinikahi kecuali satu untuk kemaslahatan perempuan. Pada masa syari`at Nabi 
kita, kedua maslahat tersebut dipelihara (Imron, 2012). Meskipun telah memiliki landasan hukum dan dasar-dasar teologis yang kuat, tampaknya praktik poligami selalu mengundang kontroversi bagi beberapa kalangan. Tema poligami, sepertinya juga, selalu menarik untuk didiskusikan. Wacana mengenai poligami tidak hanya menarik bagi kaum laki-laki, yang menjadikannya sebagai obsesi hidup, namun juga bagi perempuan yang menganggap poligami sebagai sesuatu yang membahayakan kedudukan dalam rumah tangga (Sunaryo, 2010).

Chris Barker (2016: 282) dalam bukunya yang betema Cultural Studies mengatakan bahwasannya iklan tidak hanya menawarkan barang-barang sebagai perempuan, tetapi juga hubungan personal yang membentuk posisi subjek bagi wanita yang menempatkan perempuan dalam kerja domestik patriarkal, pengasuhan anak, bersolek dan memungkinkan untuk dipoligami. Bahkan representasi perempuan dalam iklan ini membawa dalil-dalil agama untuk mengukuhkan stereotip yang dibentuk.

Kalangan Islam Liberal menolak anggapan bahwa poligami merupakan sunnah Rasulullah. Menurut mereka, sepanjang hayatnya, Nabi lebih lama bermonogami daripada berpoligami. Nabi setia monogami di tengah-tengah masyarakat yang menggangap poligami adalah lumrah. Rumah tangga Nabi SAW bersama istri tunggalnya, Khadijah binti Khuwalid RA, berlangsung selama 28 tahun. Baru kemudian dua tahun sepeninggal Khadijah Nabi berpoligami. Itupun dijalani hanya sekitar delapan tahun dari sisa hidup beliau. Pada kasus poligami, Nabi sedang mengejawantahkan ayat al-Nisa 2-3 mengenai perlindungan terhadap janda yang ditinggal mati oleh suaminya yang berjihad di jalan Allah serta anak-anak yatim. Dengan menelusuri kitab Jami' al-Ushul (Kompilasi dari enam kitab hadits ternama) karya Imam Ibn al-Atsir (544- $606 \mathrm{H}$ ), dapat diketemukan bukti bahwa poligami Nabi adalah media untuk menyelesaikan persoalaan sosial saat itu, ketika lembaga sosial yang ada belum cukup kukuh untuk memberi solusi (Huda, 2008). 


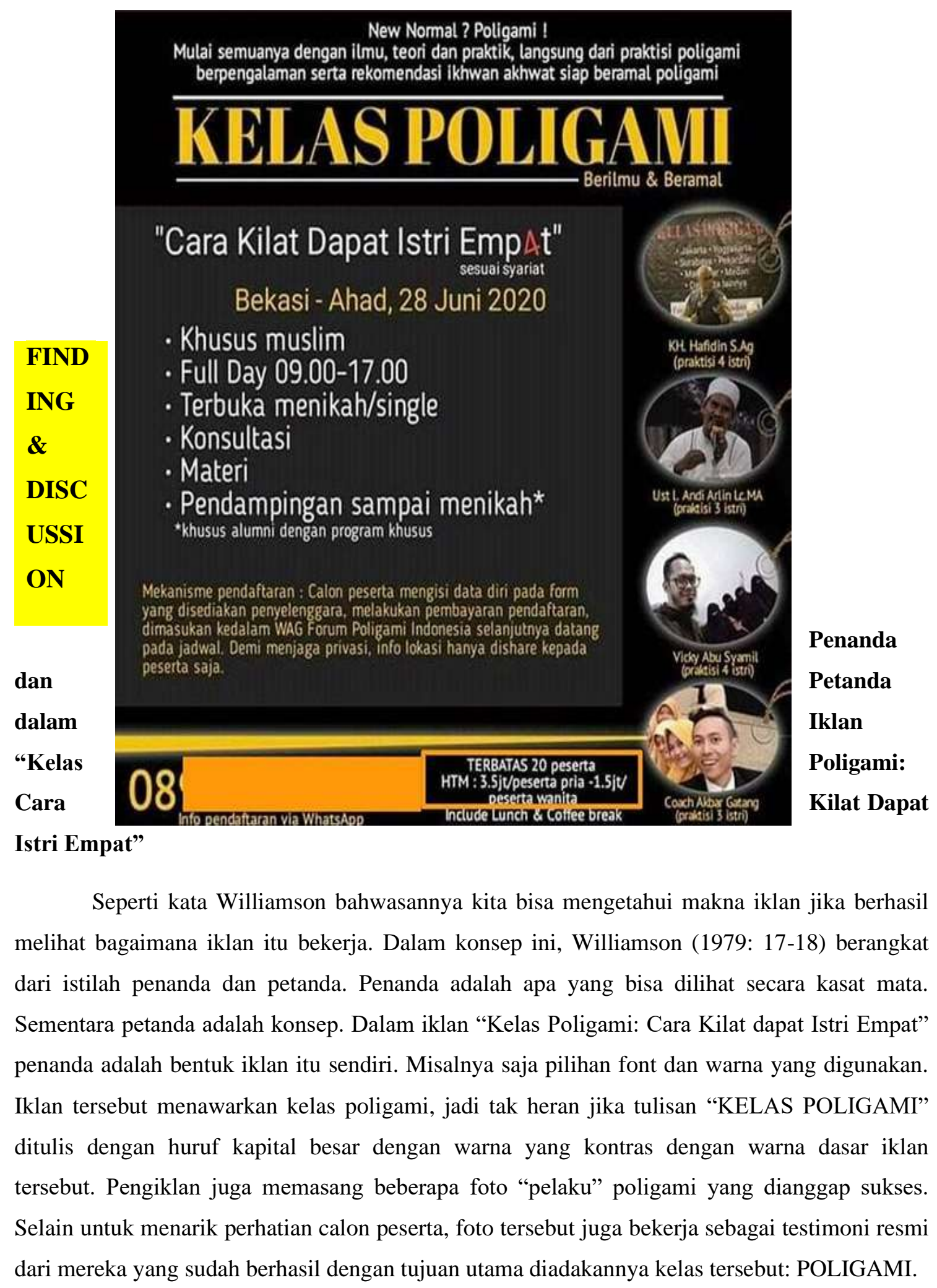


Sementara petanda adalah konsep yang ada di balik iklan tersebut. Iklan "Kelas Online: Cara Kilat dapat Istri Empat" mengajak pembaca atau audiens untuk mengikuti kelas yang diadakan oleh sebuah organisasi. Ada beberapa manfaat yang ditawarkan jika ada yang tertarik mengikuti kelas online tersebut. Pertama, tentu tentang kemungkinan istri empat yang akan didapat. Ada pula konsultasi gratis, pendampingan sampai menikah, dan beragam materi/ ilmu baru tentang poligami empat istri yang tak banyak diketahui orang.

\section{Cara Kerja Iklan "Kelas Poligami: Cara Kilat Daapat Istri Empat"}

Lebih lanjut, Williamson (dalam Rahmana (2018: 24-26) menawacanakan tiga poin penting pembentukan makna dalam iklan. Pertama, "makna dari penanda" yang melibatkan korelasi dua hal yaitu signifikansi suatu objek ditransfer pada objek yang lainnya dan tidak bersifat nonsekuensial, kedua objek tersebut memiliki hubungan satu sama lain bukan oleh alur suatu argumen atau narasi, melainkan melalui tempat keduanya di dalam gambar-gambar. Kedua, pentrasferan signifikansi tidak terjadi sebagai hal yang utuh di dalam iklan, melainkan menuntut untuk membuat hubungan tersebut. Ketiga, pentrasferan didasarkan pada kenyataan bahwa objek pertama memiliki signifikansi untuk ditransferkan; iklan pada awalnya tidak menciptakan makna tapi mengundang kita untuk membuat transaksi yang melaluinya makna itu beralih dari suatu benda ke benda lainnya. Selain itu, iklan juga berfungsi sebagai genenator yang mampu menciptakan emosi seseorang. Ada empat tahapan tentang bagaimana sebuah iklan bekerja dan menanamkan ideologi kepada khalayak menurut Judith Williamson.

\section{Tahap Pertama: Currency of Sign (Mata Uang Tanda)}

Dalam Semiotika Judith Williamson terdapat pula konsep sistem tanda yang disebut dengan referen. Referen adalah sesuatu yang berada di luar tanda (penanda-petanda). Tapi referen yang diacu oleh serangkaian tanda-tanda iklan merupakan sistem tanda yang lain, yaitu sistem mitologis (1979: 19). Nantinya, referen ini digunakan sebagai pertukaran makna yang bisa membentuk sebuah ideologi tertentu. Dalam iklan "Kelas Online: Cara Kilat dapat Istri Empat" tersebut referen yang dipertukarkan adalah: 


\section{Bagian 1: Pilihan Kata.}

Pada bagian ini, pengiklan menggunakan diksi yang tengah trending belakangan ini yaitu "New Normal". Referen yang ingin dipertukarkan dalam diksi ini adalah bawasannya poligami menjadi hal baru yang bisa dilakukan dalam menghadapi era New Normal ini. Dengan demikian, muncul sebuah makna baru bahwasannya di era setelah pandemi Covid-19 menjadi waktu yang pas untuk memulai poligami.

\section{Bagian 2: Pilihan Kata.}

Pada bagian kedua, pembuat iklan menggunakan diksi "Kelas Poligami". Frasa ini ditulis dengan huruf besar dan warna mencolok sebagai bentuk penegasan tujuan dari iklan tersebut dibuat. Selain itu, terdapat pula sub-judul "Cara Kilat dapat Istri Empat”. Referen yang hendak dipertukarkan adalah makna baru bahwa memiliki empat istri itu tidaklah sulit jika seseorang tahu caranya. Bahkan, istri empat bisa saja didapat secara kilat. Ini berarti, iklan tersebut menempatkan perempuan (istri) sebagai benda, yang bisa didapat secara kilat jika tahu caranya.

\section{Bagian 3: Foto Pemateri.}

Ada empat pemateri/praktisi yang akan hadir dalam kelas online tersebut dan foto keempatnya diletakkan di bagian kanan dari poster iklan. Selain foto, iklan tersebut juga menampilkan jumlah istri dari keempat praktisi tersebut. Referen yang dipertukarkan pada bagian ini adalah kesuksesan. Senyum yang merekah dari salah seorang pemateri yang didampingi dengan senyum keempat istrinya juga membawa kesan bahwasannya memiliki istri empat juga bisa bahagia. Hal ini sama seperti wacana Judith Williamson (1979: 27) bahwa artis atau tokoh yang digunakan dalam sebuah iklan berfungsi bukan sebagai manusia, melainkan sebagai tanda yang maknanya tidak bersifat substantial, melainkan formal, berada dalam jaringan sistem perbedaan yang berlaku dalam mitologi sosial.

\section{Tahap Kedua: Khalayak Membentuk Dirinya Melalui Tanda.}

Produk dapat menjadi makna, menjadi referen potensial bila dibeli, mengangkat kualitas abstrak seperti perasaan, tetapi bisa juga menjadi generator, menciptakan perasaan, mewujudkan apa semula abstrak. Hanya saja hal itu berlaku dalam batas-batas narasi dalam iklannya seperti pernyataan atau pernyataan mengenai apa yang akan terjadi sesudah menggunakan produk yang 
diiklankan (Williamson, 1979: 36). Iklan "Kelas Poligami: Cara Kilat dapat Istri Empat" juga menjadi generator yang seolah bisa mewujudkan sesuatu yang semula abstrak (istri empat) menjadi hampir nyata. Misalnya saja terkait foto-foto praktisi yang disematkan dalam iklan tersebut. Ibaratnya, jika sudah ada yang berhasil memiliki istri empat dengan kehidupan yang bahagia, maka banyak orang juga bisa melakukannya.

\section{Tahap Ketiga: Mengambil Makna dari Iklan}

Tahap ketiga ini adalah lanjutan dari tahap kedua. Jika tahap kedua hanya berkutat pada pembentukan makna oleh khalayak dari iklan yang ada maka dalam tahap ketiga ini, khalayak atau target iklan mengambil makna dari iklan tersebut. Iklan menawarkan subjek gambar yang punya cara kerja seperti cermin untuk mengidentifikasi yang dikonstruksi dari berbagai penanda. Gambar digunakan menjadi simbol di mana subjek dapat mengalami perasaan imajiner, ilusi (kesalahpahaman) tentang kesamaan diri dan kesatuan. Target iklan akan berhasrat untuk menjadi apa yang ditawarkan oleh iklan tersebut, untuk melengkapi dan menciptakan diri kita melalui gambar. Iklan secara aktif juga membuat kekurangan; mereka menghasilkan ruang untuk keinginan kita dan secara bersamaan menjanjikan pemenuhannya.

Dengan menyematkan foto praktisi poligami dalam iklan tersebut maka memunculkan perasaan bahwa setiap laki-laki di dunia sejatinya bisa adil meski membina rumah tangga dengan empat istri sekaligus. Selain itu, dengan tawaran bimbingan dan materi-materi khusus, beberapa pihak akan merasa sangat yakin jika poligami sejatinya bisa dilakukan oleh siapa saja. Sementara kekurangan yang ditransfer oleh iklan tersebut ada pada khalayak yang tidak tahu jurus jitu membina rumah tangga dengan empat istri. Oleh sebab itu, untuk mengisi kekuranagn tersebut, si pembuat iklan penawarkan solusinya dengan mengadakan kelas poligami secara online lengkap dengan bimbingan sampai menikah.

\section{Tahap Keempat: Ideologi Iklan dan Ego Individu}

Sesudah membentuk subjek-subjek dalam batas kelompok, iklan membentuknya sebagai individu, iklan itu memecah individu menjadi ego yang terfragmentasikan yang kemudian disatukan kembali oleh produk. Subjek itu didekonstruksi hanya untuk dibentuk 
kembali menjadi satu kesatuan dalam iklan. Identitas multiple dianggap sebagai ilusi sehingga multiplisitas yang diimplikasikan berpusat pada seseorang dan oleh produk (Williamson, 1979: 55). Setelah khalayak menciptakan makna, mereka akan membawa makna tersebut ke dalam dirinya. Saat inilah ideologi akan tebentuk sebab makna itu mengatur hubungan kita dengan orang lain dan / atau kelompok lain. Seperti halnya iklan menciptakan diferensiasi antara produk, sebagian ada yang suka dan yang lain tidak begitu menyukainya, mereka menciptakan diferensiasi sosial antara kelompok orang.

Iklan "Kelas Poligami: Cara Kilat Dapat Istri Empat" juga membentuk manusia menjadi dua golongan, yakni golongan yang pro-poligami dan yang menentangnya. Golongan propoligami ini adalah imbas dari ideologi iklan poligami dan berbagai mitos-mitos indah yang ditawarkankannya. Pentransferan makna bahwa poligami itu bisa dilakukan dari sebuah iklan membentuk kelompok tertentu untuk mengikutinya. Apalagi jika hal tersebut dianggap membawa keuntungan sendiri bagi pelaksananya, misalnya tentang iming-iming surga atau kebahagian yang hakiki tanpa mempedulikan beragam aspek psikologis manusia lainnya.

\section{Kesimpulan}

Pada iklan Kelas Poligami saat New Normal: Cara Kilat Dapat Istri Empat” jelas bahwa ada ideologi yang ingin disampaikan. Iklan tersebut bukan hanya bersifat memberitahu public untuk kepentigan komersil. Akan tetapi, ada makna di balik tujuan dibuatnya iklan tersebut. Pada akhirnya, iklan tersebut mampu menggolongkan manusia dalam dua kelompok tertentu.Pertama adalah mereka yang pro terhadap poligami. Sementara kemlompok kedua merupakan mereka yang kontrak terhadap hal tersebut.

Dengan menyematkan foto praktisi poligami dalam iklan poligami akan memunculkan perasaan bahwa setiap laki-laki di dunia sejatinya bisa adil meski membina rumah tangga dengan empat istri sekaligus. Ini adalah wujud dari ideologi yang ditransmisikan oleh praktisi dan diinternalisasikan oleh audiens iklan poligami. Selain itu, dengan tawaran bimbingan dan materi-materi khusus, beberapa pihak akan merasa sangat yakin jika poligami sejatinya bisa dilakukan oleh siapa saja. Sementara kekurangan yang ditransfer oleh iklan tersebut ada pada khalayak yang tidak tahu jurus jitu membina rumah tangga dengan empat istri. Oleh sebab itu, untuk mengisi kekuranagn tersebut, si pembuat iklan penawarkan solusinya dengan 
mengadakan kelas poligami secara online lengkap dengan bimbingan sampai menikah. Pada tataran ini ideologi akan lebih mudah berpindah dan diterima, mengingat dunia digital tidak mengenal batas seperti dunia fisik. Ini artinya, di masa depan, dengan menguatnya konservatisme di dalam tubuh Islam Indonesia iklan poligami akan lebih cenderung mendapat tempat. Ideologi yang ditawarkan juga berpotensi laris manis di kalangan kelas menengah muslim konservatif.

\section{CONCLUSIONS (خلاصة \خاتمة)}

There are 4 types of idiom expressions used by characters in the Megamind movie, namely the first type of Phrasal Verb Idiom, 54 idioms are consisting of 34 idioms found in Megamind characters, 9 idioms found in Metroman character, and 11 idioms contained in Minion character, the second is Tournure Idiom, there are 5 idioms found in Megamind character, the third types of Phrasal Compound Idioms, there are 93 idioms found, 63 idioms found in Megamind character, 12 idioms contained in Metroman character, and 18 idioms contained in Minion character, and the fourth type of Incorporating Verbs Idioms found 23 idioms, 16 idioms on Megamind character, 3 idioms on Metroman character, and 4 idioms on Minion character. In analyzing the meaning of idiomatic expressions used by the characters in the Megamind movie, the writer defines these expressions based on the utterances spoken by the characters and based on the impressions in the movie. In the Irreversible Binomial idiom type, the researcher did not find a single character in the Megamind movie character who used this type of idiom.

\section{BIBILIOGRAPHY (قائماة المراجع)}

\section{References :}

Butt, S. (2008). Polygamy and mixed marriage in Indonesia: Islam and the marriage law in the courts.

Chris Barker. 2016. Cultural Studies: Theory and Practice, terj. Nurhadi, Cultural Studies: Teori \& Praktik (Cet. 10; Bantul: Kreasi Wacana.

Dirks, N. B., Eley, G., \& Ortner, S. B. (1994). Culture/power/history: A reader in contemporary social theory. Princeton University Press. 
Horton, A. L., \& Williamson, J. A. (1988). Abuse and religion: When praying isn't enough. Lexington Books/DC Heath and Com.

Huda, N. (2008). Poligami dalam Pemikiran Kalangan Islam Liberal.

Imron, A. (2012). Menimbang Poligami dalam Hukum Perkawinan. QISTIE, 6(1).

Jawad, H. A. (1991). Women and the question of polygamy in Islam. Islamic Quarterly, 35(3), 181.

Johnson, H. (2004). There are worse things than being alone: Polygamy in Islam, past, present, and future. Wm. \& Mary J. Women \& L., 11, 563.

Marcotte, R. D. (2001). Šạrūr, the Status of Women, and Polygamy in Islam. Oriente moderno, 81(2-3), 313-328.

Muhammad Mufid. 2019. Etika Dan Filsafat Komunikasi. Ed. I. (Cet. I; Jakarta: Kencana)

Nurgiyantoro, Burhan. 2012. Teori Pengkajian Fiksi. Yogyakarta: Gadjah Mada University Press.

Nurmila, N. (2009). Women, Islam and everyday life: Renegotiating polygamy in Indonesia. Routledge.

Philips, A. A. B., \& Jones, J. (2005). Polygamy in Islam. Islamic Books.

Rehman, J. (2007). The sharia, Islamic family laws and international human rights law: Examining the theory and practice of polygamy and talaq. International Journal of Law, Policy and the Family, 21(1), 108-127.

Rodgers-Miller, B. D. (2004). Out of Jahiliyya: Historic and Modern Incarnations of Polygamy in the Islamic World. Wm. \& Mary J. Women \& L., 11, 541.

Rohman, A. (2013). Reinterpret polygamy in Islam: A case study in Indonesia. Rohman, Arif.(2013). Reinterpret Polygamy in Islam: A Case Study in Indonesia. Int J Hum \& Soc Sci Inv, 2(10), 68-74.

Siswati E. (2014). Representasi Perempuan Dalam Iklan. 109-185. Volume 11, No 2, Desember 2014: 179-194 Jurnal Ilmu Komunikasi

Sunaryo, A. (2010). Poligami di Indonesia (Sebuah analisis normatif-sosiologis). Yinyang: Jurnal Studi Islam Gender dan Anak, 5(1), 143-167.

Wells, L. (1992). Judith Williamson, Decoding. Reading into cultural studies, 165.

Williamson, J. (1978). Decoding advertisements: ideology and meaning in advertising. Marion Boyers.

Williamson, Judith. 1979. Decoding Advertisements: Ideologi and Meaning in Advertising. New York: Marion BoyarsPublishers Inc.

Williamson, J. (1981). How does girl number twenty understand ideology. Screen Education, 40(2), 80-87.

Williamson, J. (1983). Images of ‘Woman’. Screen, 24(6), 102-116. 
Williamson, J. (1986). Consuming passions: The dynamics of popular culture. Marion Boyars.

Williamson, J. (1986). The Dynamics of Popular Culture. New York: Marion Boyars). WilliamsonConsuming Passions: the Dynamics of Popular Culture1985.

Williamson, J. (2000). A currency of signs. Advertising \& Society Review, 1(1).

2007. Decoding Advertisements: Membedah Ideologi dan Makna dalam Periklanan, terj. Saleh Rahmana (cet 1 Yogyakarta dan Bandung: Jalasutra) 